\title{
Short communication: Prevalence and antibiotic resistance of Staphylococcus aureus isolated from bovine clinical mastitis
}

\author{
Hossein Jamali, ${ }^{\star}$ Behrad Radmehr, $†$ and Salmah Ismail*1 \\ ${ }^{*}$ Biohealth Science Program, Institute of Biological Science, Faculty of Science, University of Malaya, 50603, Kuala Lumpur, Malaysia \\ †Department of Food Hygiene and Quality Control, Faculty of Veterinary Medicine, Islamic Azad University-Karaj Branch, Karaj 31485-313, Iran
}

\begin{abstract}
The aims of this study were to determine the prevalence and antibiotic resistance of Staphylococcus aureus isolated from bovine clinical mastitis in Varamin, Tehran Province, Iran. All of the isolated Staph. aureus were identified by morphology and culture and confirmed using the API Staph identification system (bioMérieux, Marcy-l'Étoile, France). Antibiotic resistance genes were detected by PCR with oligonucleotide primers specific for each gene. Staphylococcus aureus was recovered from 43 of $207(20.1 \%)$ bovine clinical milk samples. Using disk diffusion, methicillin-resistant Staph. aureus was detected in 5 of 43 (11.6\%) samples. The pathogen showed high resistance against penicillin G $(86 \%)$ and tetracycline $(76.7 \%)$. The blaZ (penicillin) (86\%), tet $M$ (tetracycline), and ermC (erythromycin) genes $(39.5 \%$ each) were the most prevalent antibiotic resistance genes. The findings of this study are useful for designing specific control programs for bovine clinical mastitis caused by Staph. aureus in this region of Iran.
\end{abstract}

Key words: Staphylococcus aureus, clinical mastitis, antibiotic susceptibility, resistance gene

\section{Short Communication}

Staphylococcus aureus is a major cause of clinical and subclinical mastitis in dairy herds. The pathogen can be transmitted from cows, the environment, and equipment into the udder via the milking machine and other fomites (e.g., milkers' hands). In Iran, bovine mastitis is often treated with tetracycline, penicillin, clindamycin, erythromycin, oxacillin, or ciprofloxacin. However, the practice of incorporating antibiotics into feeds to control and treat diseases in cows on dairy farms has increased, and antibiotic administration in animals could be one of the main causes of antibiotic

Received September 20, 2013.

Accepted December 30, 2013.

${ }^{1}$ Corresponding author: Salmah_r@um.edu.my resistance in pathogens (Schwartz et al., 2003; Jamali et al., 2013).

The antibiotic resistance genes mecA (oxacillin); tet $M$, tetK, tetL (tetracycline); ermA, ermB, ermC, erm $T, m s r A, m s r B, m p h C$ (erythromycin); blaZ (penicillin); aacA-aphD (gentamicin); ant(4')-Ia (kanamycin and tobramycin); qnrA (fluoroquinolone); lnuA (lincomycin); fexA (chloramphenicol); cfr (multidrug resistance; phenicols-lincosamides-oxazolidinonespleuromutilin-streptogramins A); and $d f r G, d f r K$, and $d f r S 1$ (trimethoprim) have been reported among Staph. aureus isolates in previous studies (Lina et al., 1999; Martineau et al., 2000a,b; Mammeri et al., 2005; Kehrenberg and Schwarz, 2006; Lüthje and Schwarz, 2006; Fessler et al., 2010; Argudín et al., 2011; Gao et al., 2012). Methicillin-resistant Staph. aureus (MRSA) is a significant cause of human nosocomial infections in many parts of the world. The aim of this study was to investigate the prevalence, antibiotic resistance profiles, and related resistance genes among these isolates of Staph. aureus isolated from bovine clinical mastitis cases in Varamin, Tehran Province, Iran.

Two hundred and seven mastitic milk samples were collected from one infected teat of cows suffering from clinical mastitis by field veterinarians distributed throughout Varamin, Iran, from November 2008 to July 2010. Samples were transported on ice to the laboratory within $3 \mathrm{~h}$ of sampling.

Isolation of Staph. aureus in this study was carried out according to National Mastitis Council (1990) methods. Briefly, $15 \mu \mathrm{L}$ of each mastitic milk sample was plated on blood agar base (Oxoid, Basingstoke, UK) with $5 \%$ sheep blood and was incubated for $24 \mathrm{~h}$ at $37^{\circ} \mathrm{C}$ under anaerobic condition. Presumptive colonies of Staph. aureus (based on colony morphology) were confirmed using the API Staph identification system (bioMérieux, Marcy-l'Étoile, France).

Antibiotic susceptibility was determined by the disk diffusion method after culture on Mueller Hinton agar (Oxoid; CLSI, 2006). The following panel of antibiotic agents (Oxoid) was applied: tetracycline, penicillin, clindamycin, erythromycin, oxacillin, ciprofloxacin, chloramphenicol, gentamicin, cefoxitin, trimethoprim- 
sulphametoxazol, kanamycin, lincomycin, tobramycin, streptomycin, and quinupristin-dalfopristin. Clindamycin-susceptible, erythromycin-resistant isolates were tested for inducible clindamycin resistance by disk diffusion induction test (D-test), and isolates positive for the D-test were considered resistant to clindamycin (Jorgensen et al., 2004).

The PCR assays were performed as described previously for the antibiotic resistance genes mecA (oxacillin resistance); tet $M$, tet $K$, tet $L$ (tetracycline resistance); ermA, ermB, erm C, erm T, msrA, msrB, mphC (erythromycin resistance); blaZ (penicillin resistance); aacA$a p h D$ (gentamicin resistance); qnrA (fluoroquinolone resistance); $\ln u A, \operatorname{lnu} B$ (lincomycin resistance); vgaA, $v g a B, \quad v g a C$ (quinupristin-dalfopristin resistance); cat::pC221, cat::pC194, cat::pC223; fexA (chloramphenicol resistance); $c f r$ (multidrug resistance); $d f r G$, $d f r K, d f r S 1$ (trimethoprim resistance); $c f x A$ (cefoxitin resistance); ant(4')-Ia (kanamycin and tobramycin resistance); and ant(6)-Ia (streptomycin resistance) (Ounissi and Courvalin, 1987; Sutcliffe et al., 1996; Bozdogan et al., 1999; Lina et al., 1999; Schmitz et al., 1999; Martineau et al., 2000a,b; Trzcinski et al., 2000; Werner et al., 2001; Avelar et al., 2003; Kehrenberg and Schwarz, 2005; Mammeri et al., 2005; Kehrenberg and Schwarz, 2006; Lüthje and Schwarz, 2006; Fessler et al., 2010; Argudín et al., 2011; Gao et al., 2012).

Staphylococcus aureus isolates were detected in 43 of $207(20.1 \%)$ bovine clinical mastitis samples. Five $(11.6 \%)$ isolates were identified as MRSA by antibiotic susceptibility (resistant to oxacillin) and confirmed by mecA gene detection (Table 1). The Staph. aureus isolates showed resistance to penicillin G (86\%), tetracycline $(76.7 \%)$, erythromycin $(39.5 \%)$, clindamycin (34.9\%), cefoxitin $(16.3 \%)$, oxacillin, chloramphenicol, trimethoprim-sulfamethoxazole $(11.6 \%$ each), lincomycin $(9.3 \%$ each), gentamicin $(7 \%)$, quinupristindalfopristin and streptomycin (2.3\% each). Fifteen clindamycin-susceptible, erythromycin-resistant isolates were tested by D-test. Inducible clindamycin resistance was observed in 9 of $15(60 \%)$ of these isolates and were reported as clindamycin resistant (Table 1). All Staph. aureus isolates were susceptible to ciprofloxacin, kanamycin, and tobramycin.

The correlation between phenotypic antibiotic resistance and PCR results is shown in Table 1. All Staph. aureus isolates resistant to penicillin G, gentamicin, and oxacillin contained the blaZ, aacA-aphD, and mecA genes, respectively. For cefoxitin resistance, the $c f x A$ gene was present in 6 of $7(85.7 \%)$ of the cefoxitinresistant isolates. Out of 33 tetracycline resistant isolates, $81.8,51.5$, and $12.1 \%$ isolates contained the tet $M$, tet $K$, and tet $L$ genes, respectively, with each gene found alone or in combination in the following isolate per- centages: tetK $(15.2 \%)$, tetM $(45.5 \%)$, tetK tetL $(3 \%)$, tetL tet $M(3 \%)$, tetK tet $M(27.3 \%)$, and tetK tetL tet $M$ (6.1\%). For erythromycin resistance, the erm $C$ gene was present in all erythromycin-resistant isolates, alone $(41.2 \%)$ or together with ermB $(23.5 \%)$, ermA (5.9\%), both ermB and ermA genes (17.6\%), or erm T (11.8\%). The $m s r A$ and $m s r B$ genes were detected in 29.4 and $52.9 \%$ of erythromycin-resistant isolates, respectively. Furthermore, the $m p h C$ gene was found in 10 of 17 $(58.8 \%)$ of the erythromycin-resistant isolates. Four and 1 of the trimethoprim-sulphametoxazol-resistant isolates harbored the $d f r G$ and $d f r K$ genes, respectively. No isolate was positive for the trimethoprim-resistance gene $d f r S 1$. Moreover, no isolate was positive for the chloramphenicol-resistance cat::pC221, cat::pC194, cat::pC223 genes, whereas the fexA gene was detected in 1 isolate. This isolate also carried lincomycin resistance gene $\ln u A$ and the multidrug resistance gene, $c f r$. The quinupristin-dalfopristin resistant isolate was negative for the vgaA, vgaB, and vgaC genes. No qnrA (fluoroquinolone resistance gene), ant(4')-Ia (kanamycin and tobramycin resistance gene), or ant(6)-Ia (streptomycin resistance gene) were detected in the tested isolates.

Although the prevalence of Staph. aureus from bovine mastitis has frequently been reported in other countries, few published studies have addressed the problem in Iran. In the current study, Staph. aureus was detected in $20.1 \%$ of the 207 mastitic milk samples. However, in prior studies, Dastmalchi Saei et al. (2009) and Momtaz et al. (2011) detected Staph. aureus in 15.7 and $23.9 \%$ of combined clinical and subclinical mastitis, respectively, in 2 different provinces of Iran. Moreover, Boynukara et al. (2008) and Oliveira et al. (2012) reported that 22.1 and $15.2 \%$ of bovine mastitic milk samples in Turkey and Brazil were contaminated with Staph. aureus, respectively. Methicillin-resistant Staph. aureus is an important bacterial pathogen in humans and animals worldwide, but to the best of our knowledge, there is no published information regarding MRSA from bovine clinical mastitis in Iran. Although the prevalence of MRSA in bovine clinical samples was $11.6 \%$ (5/43) in this study, Vanderhaeghen et al. (2010) detected MRSA in $9.3 \%$ of clinical and subclinical mastitis cases in Belgian cows. Variations in findings may be attributable to different sample sizes and study locations.

Over the last decade, penicillin and tetracycline have been administered to animals through food to treat infectious diseases, particularly on dairy farms in Iran (Jamali et al., 2013). The high resistance rate of Staph. aureus isolated from bovine clinical mastitis to penicillin $\mathrm{G}$ and tetracycline could be due to widespread use of these antibiotics on dairy farms. Our findings are in agreement with earlier results: a high resistance 


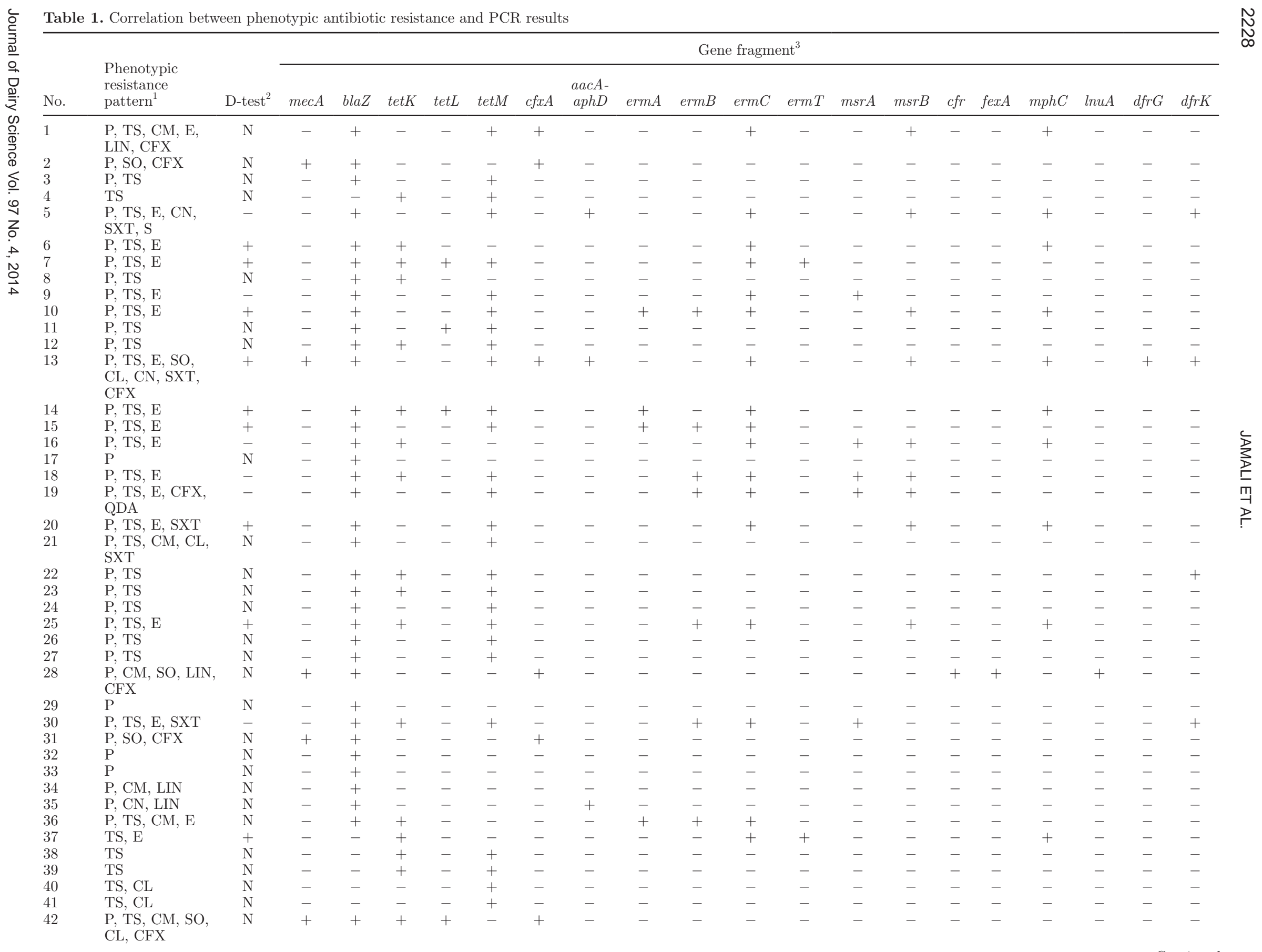


of Staph. aureus to penicillin G and tetracycline was reported by Gao et al. (2012).

The high prevalence of the blaZ, tetM, and ermC genes in the current study is in agreement with an earlier report in which a high prevalence rate of blaZ, tet $M$, and $\mathrm{erm} C$ genes was reported by Gao et al. (2012). The presence of resistant Staph. aureus isolates in bovine mastitis and transmission of the pathogen through contaminated milk during milking could cause mastitis in a dairy herd, which is tenacious and difficult to treat. In addition, antibiotic-resistant pathogens can be transmitted to the farm workers and veterinarians who come in contact with these animals directly or indirectly.

In summary, the high prevalence of Staph. aureus (20.1\%), as well as penicillin G- (86\%) and tetracycline-resistant $(76.6 \%)$ isolates, was confirmed by the presence of resistance genes in this study. The findings indicate that surveillance programs are necessary to screen for the incidence and antibiotic resistance of Staph. aureus isolates in bovine mastitis cases in this region of Iran.

\section{ACKNOWLEDGMENTS}

This study was supported by OCAR chancellery of University Malaya (Kuala Lumpur, Malaysia) under grant numbers A-21010-DA674 and A-21010-DA677.

\section{REFERENCES}

Argudín, M. A., B.-A. Tenhagen, A. Fetsch, J. Sachsenröder, A. Käsbohrer, A. Schroeter, J. A. Hammerl, S. Hertwig, R. Helmuth, J. Bräunig, M. C. Mendoza, B. Appel, M. R. Rodicio, and B. Guerra. 2011. Virulence and resistance determinants of German Staphylococcus aureus ST398 isolates from nonhuman sources. Appl. Environ. Microbiol. 77:3052-3060.

Avelar, K. E. S., K. Otsuki, A. C. P. Vicente, J. M. Vieira, G. R. de Paula, R. M. Domingues, and M. C. Ferreira. 2003. Presence of the cfxA in Bacteroides distasonis. Res. Microbiol. 154:369-374.

Boynukara, B., T. Gulhan, M. Alisarli, K. Gurturk, and H. Solmaz. 2008. Classical enterotoxigenic characteristics of Staphylococcus aureus strains isolated from bovine subclinical mastitis in Van, Turkey. Int. J. Food Microbiol. 125:209-211.

Bozdogan, B., L. Berrezouga, M. S. Kuo, D. A. Yurek, K. A. Farley, B. J. Stockman, and R. Leclercq. 1999. A new resistance gene, lin $B$, conferring resistance to lincosamides by nucleotidylation in Enterococcus faecium HM1025. Antimicrob. Agents Chemother. 43:925-929.

CLSI (Clinical and Laboratory Standards Institute). 2006. Methods for Antimicrobial Dilution and Disk Susceptibility Testing of Infrequently Isolated or Fastidious Bacteria. Approved Guideline M45A; Vol. 26, No. 19. Clinical and Laboratory Standards Institute, Wayne, PA.

Dastmalchi Saei, H., M. Ahmadi, K. Mardani, and R. A. Batavani. 2009. Molecular typing of Staphylococcus aureus isolated from bovine mastitis based on polymorphism of the coagulase gene in the north west of Iran. Vet. Microbiol. 137:202-206.

Fessler, A., C. Scott, K. Kadlec, R. Ehricht, S. Monecke, and S. Schwarz. 2010. Characterization of methicillin-resistant Staphylococcus aureus ST398 from cases of bovine mastitis. J. Antimicrob. Chemother. 65:619-625. 
Gao, J., M. Ferreri, F. Yu, X. Liu, L. Chen, J. Su, and B. Han. 2012. Molecular types and antibiotic resistance of Staphylococcus aureus isolates from bovine mastitis in a single herd in China. Vet. J. 192:550-552.

Jamali, H., B. Radmehr, and K. L. Thong. 2013. Prevalence, characterisation, and antimicrobial resistance of Listeria species and Listeria monocytogenes isolates from raw milk in farm bulk tanks. Food Contr. 34:121-125.

Jorgensen, J. H., S. A. Crawford, M. L. McElmeel, and K. R. Fiebelkorn. 2004. Detection of inducible clindamycin resistance of staphylococci in conjunction with performance of automated broth susceptibility testing. J. Clin. Microbiol. 42:1800-1802.

Kehrenberg, C., and S. Schwarz. 2005. Florfenicol-chloramphenicol exporter gene fexA is part of the novel transposon Tn558. Antimicrob. Agents Chemother. 49:813-815.

Kehrenberg, C., and S. Schwarz. 2006. Distribution of florfenicol resistance genes fexA and cfr among chloramphenicol-resistant Staphylococcus isolates. Antimicrob. Agents Chemother. 50:1156-1163.

Lina, G., A. Quaglia, M. E. Reverdy, R. Leclercq, F. Vandenesch, and J. Etienne. 1999. Distribution of genes encoding resistance to macrolides, lincosamides, and streptogramins among staphylococci. Antimicrob. Agents Chemother. 43:1062-1066.

Lüthje, P., and S. Schwarz. 2006. Antimicrobial resistance of coagulase negative staphylococci from bovine subclinical mastitis with particular reference to macrolide-lincosamide resistance phenotypes and genotypes. J. Antimicrob. Chemother. 57:966-969.

Mammeri, H., M. Van De Loo, L. Poirel, L. Martinez-Martinez, and P. Nordmann. 2005. Emergence of plasmid-mediated quinolone resistance in Escherichia coli in Europe. Antimicrob. Agents Chemother. 49:71-76.

Martineau, F., F. J. Picard, L. Grenier, P. H. Roy, M. Ouellette, and M. G. Bergeron.. 2000a. Multiplex PCR assays for the detection of clinically relevant antibiotic resistance genes in staphylococci isolated from patients infected after cardiac surgery. J. Antimicrob. Chemother. 46:527-534.

Martineau, F., F. J. Picard, N. Lansac, C. Menard, P. H. Roy, M. Ouellette, and M. G. Bergeron. 2000b. Correlation between the resistance genotype determined by multiplex PCR assays and the antibiotic susceptibility patterns of Staphylococcus aureus and Staphylococcus epidermidis. Antimicrob. Agents Chemother. 44:231-238.
Momtaz, H., E. Tajbakhsh, E. Ebrahimi, and M. Momeni. 2011. Coagulase gene polymorphism of Staphylococcus aureus isolated from clinical and sub-clinical bovine mastitis in Isfahan and Chaharmahal va Bakhtiari provinces of Iran. Comp. Clin. Path. 20:519-522.

National Mastitis Council. 1990. Microbiological Procedures for the Diagnosis of Bovine Udder Infection. National Mastitis Council Inc., Arlington, VA.

Oliveira, L., H. Langoni, C. Hulland, and P. L. Ruegg. 2012. Minimum inhibitory concentrations of Staphylococcus aureus recovered from clinical and subclinical cases of bovine mastitis. J. Dairy Sci. 95:1913-1920.

Ounissi, H., and P. Courvalin. 1987. Appendix B. Nucleotide sequences of streptococcal genes. Page 275 in Streptococcal Genetics. J. J Ferretti and R. I. I. I. Curtis, ed. American Society for Microbiology, Washington, DC.

Schmitz, F. J., A. C. Fluit, M. Gondolf, R. Beyrau, E. Lindenlauf, J. Verhoef, H. P. Heinz, and M. E. Jones. 1999. The prevalence of aminoglycoside resistance and corresponding resistance genes in clinical isolates of staphylococci from 19 European hospitals. J. Antimicrob. Chemother. 43:253-259.

Schwartz, T., W. Koknen, U. Obst, and B. Jansen. 2003. Detection of antibiotic resistant bacteria and their resistance genes in wastewater, surface water, and drinking water biofilms. FEMS Microbiol. Ecol. 43:325-335.

Sutcliffe, J., T. Grebe, A. Tait-Kamradt, and L. Wondrack. 1996. Detection of erythromicin-resistant determinants by PCR. Antimicrob. Agents Chemother. 40:2562-2566.

Trzcinski, K., B. S. Cooper, W. Hryniewicz, and C. G. Dowson. 2000. Expression of resistance to tetracyclines in strains of methicillinresistance Staphylococcus aureus. J. Antimicrob. Chemother. 45:763-770.

Vanderhaeghen, W., T. Cerpentier, C. Adriaensen, J. Vicca, K. Hermans, and P. Butaye. 2010. methicillin-resistant Staphylococcus aureus (MRSA) ST398 associated with clinical and subclinical mastitis in Belgian cows. Vet. Microbiol. 144:166-171.

Werner, G., C. Cuny, F. J. Schmitz, and W. Witte. 2001. Methicillinresistant, quinupristin-dalfopristin-resistant Staphylococcus aureus with reduced sensitivity to glycopeptides. J. Clin. Microbiol. $39: 3586-3590$. 